\title{
A LESS INVASIVE METHOD OF REDUCING THE INCIDENCE OF POST-ENDOSCOPIC RETROGRADE CHOLANGIOPANCREATOGRAPHY PANCREATITIS: INTRAVENOUS DICLOFENAC SODIUM VERSUS PLACEBO
}

\author{
IAN CHIK ${ }^{1}$, RAZMAN JARMIN ${ }^{1 *}$, AFFIRUL ARIFFIN ${ }^{2}$, HAIROL OTHMAN ${ }^{1}$, ZAMRI ZUHDI ${ }^{1}$, AZLANUDIN AZMAN ${ }^{1}$, \\ NIK RITZA KOSAI NIK MAHMOOD ${ }^{3}$
}

\begin{abstract}
${ }^{1}$ Hepatobiliary Unit, Department of Surgery, Universiti Kebangsaan Malaysia Medical Centre, Malaysia. ${ }^{2}$ Department of Surgery, Universiti Sains Islam Malaysia, Malaysia. ${ }^{3}$ Department of Surgery, Universiti Kebangsaan Malaysia Medical Centre, Malaysia.
\end{abstract}

Email: drrazman@yahoo.com.au

Received: 06 April 2018, Revised and Accepted: 08 June 2018

ABSTRACT

Objective: The purpose of this study is to reduce the incidence of post-endoscopic retrograde cholangiopancreatography (ERCP) pancreatitis (PEP) by the administration of intravenous (IV) diclofenac sodium.

\begin{abstract}
Methods: This is a prospective, randomized, double-blinded control study. This study was performed in the hepatobiliary unit of general surgery department in University Kebangsaan Malaysia Medical Centre (UKMMC) from May 2015 to May 2016. A total of 128 patients were enrolled in this study. 59 patients were randomized into the treatment arm, while 63 were randomized into the control group. Patients were randomized by envelope system, and patients in the treatment arm received $75 \mathrm{mg}$ of diclofenac sodium intravenously, within $30 \mathrm{~min}$ of ERCP commencement. Both groups were observed for PEP post-ERCP and their pain score recorded. Patients' demographic data were also observed.
\end{abstract}

Results: A total of 122 patients were included in the study, with 59 patients randomized into the treatment arm and 63 into the placebo arm. There was an increase of $7.6 \%$ PEP rates in the placebo group ( $12.7 \%$ vs. $5.1 \%$ in the treatment arm). However, this was not statistically significant ( $\mathrm{p}=0.142$ )

Conclusion: This study shows that IV diclofenac sodium can decrease PEP but is not statistically significant.

Keywords: Anti-inflammatory agents, Nonsteroidal, Cholangiopancreatography, Endoscopic retrograde, Pain, Prospective studies.

(C) 2018 The Authors. Published by Innovare Academic Sciences Pvt Ltd. This is an open access article under the CC BY license (http://creativecommons. org/licenses/by/4. 0/) DOI: http://dx.doi.org/10.22159/ajpcr.2018.v11i10.26474

\section{INTRODUCTION}

Endoscopic retrograde cholangiopancreatography (ERCP) is an important tool used for diagnostic and therapeutic purposes for both benign and malignant diseases.

There are a few complications from ERCP, but post-ERCP pancreatitis (PEP) is the most common, with the rate of incidence of post-ERCP PEP, is anywhere between 1 and 15\% [1-6], but in higher risk patients, the risk may be more than $25 \%$ [7]. Severe PEP was only seen in $0.4 \%$ of patients, while there was only $0.11 \%$ mortality [5]. In two of the prospective studies published, the rate of severe PEP was only $0.32 \%$ of 7252 patients [1,2]. In our center of practice, Pusat Perubatan Universiti Kebangsaan Malaysia, the rate of PEP was 14.5\% in 2012.

At current, multiple medications have been used in attempts to reduce the incidence of PEP, but only rectally administered nonsteroidal antiinflammatory drugs (NSAIDs) have been shown to have any efficacy $[8,9]$. There have been many meta-analyses that review the efficacy of NSAIDs in decreasing the risk of PEP overall. However, rectal NSAIDs (in particular, diclofenac and indomethacin) are most effective [8].

There are only a few studies that look at other routes of administration of NSAIDs in reducing PEP. A meta-analysis by Ding X [8] examines 10 randomized trials on NSAIDs in reduction of post-ERCP PEP, analyzing six trials on rectal NSAID, one oral NSAID, one intramuscular NSAID, and one intravenous (IV) NSAID. The result of this meta-analysis showed that rectal NSAID favored a lower incidence of post-ERCP PEP, while other forms were not favorable. Senol (2009) showed a lower risk ratio in using intramuscular diclofenac [10].
However, none of these papers examined the role of IV diclofenac in reducing post-ERCP PEP episodes, and they have been no proper study examining the effects of IV diclofenac in reduction of PEP rates. IV diclofenac is the choice for study as it is relatively cheap, easily attainable with less invasive delivery; hence, its use in reduction of PEP post-ERCP is beneficial.

\section{METHODS}

This study was done as a requirement for completion of Masters of Surgery program.

It is a double-blinded, randomized controlled clinical trial, which took patient samples from all patients undergoing ERCP under hepatobiliary unit University Kebangsaan Malaysia Medical Centre (UKMMC) from May 2015 to May 2016. All patients who are able to give consent were included into the study, whereas patients, who had contraindications or allergies to NSAIDs, or did not consent, had recent PEP in the past 5 days or already on NSAIDs were excluded from the study.

This study was done in a single center, in UKMMC, and patients were randomized through the envelope system and as per CONSORT protocol. The medical assistants in the procedure room randomize the patients to either treatment with IV diclofenac sodium $75 \mathrm{mg}$ within 30 min commencement of procedure, or normal saline as a placebo. The surgeon who performs the ERCP and the assessor post-ERCP is unaware of the intervention administered. Post-procedure, patients are assessed $4 \mathrm{~h}$ post-ERCP clinically and biochemically to ascertain the development of PEP. Approval from the Faculty of Medicine and Ethics 
committee of UKMMC was granted before commencement of the study with project code FF-2015- 239.

\section{Data collection table and statistical analysis}

Data were summarized by descriptive statistics. Computer-assisted analysis was carried out at the end of the study. For categorical data, Pearson's Chi-square test was used. Statistical significance is taken at $\mathrm{p}<0.05$ (Fig. 1)

\section{RESULTS}

This study was carried out between the period of June 2015 and May 2016, and patients were selected from ERCP carried out in the Department of Hepatobiliary, UKMSC, Malaysia, under emergency or elective setting. There were a total of 276 patients during this period of time, but only 181 patients fulfilled the inclusion criteria. 35 patients did not consent for the study, and 146 were plan for randomization, but 18 did not proceed for the procedure. In total, 128 patients were randomized, 64 each to the treatment and placebo arm. In both arms, there was error in protocol, leaving 59 patients in the treatment arm and 63 patients in the placebo arm

Patients randomized were evenly matched (not statistically significant) in age groups, gender or comorbidities. In the treatment arm, there were 26 males $(44.1 \%)$ and 33 females $(55.9 \%)$. There were 35 males $(57.4 \%)$ and 28 females (44.4\%) in the placebo arm. The mean age for the treatment group was 52.86 years $(95 \%$ confidence interval [CI] $48.85-56.88)$ and 55.70 years (95\% CI 51.48-59.92). The majority race of both treatment and placebo arms, respectively, were the Malays; 36 and 33, followed by the Chinese; 17 and 27, the Indians; 3 and 2, and other races; 3 and 1.

The majority of patients undergoing ERCP were for obstructive jaundice (60 or $49.1 \%$ ), followed by patients who were reassessed

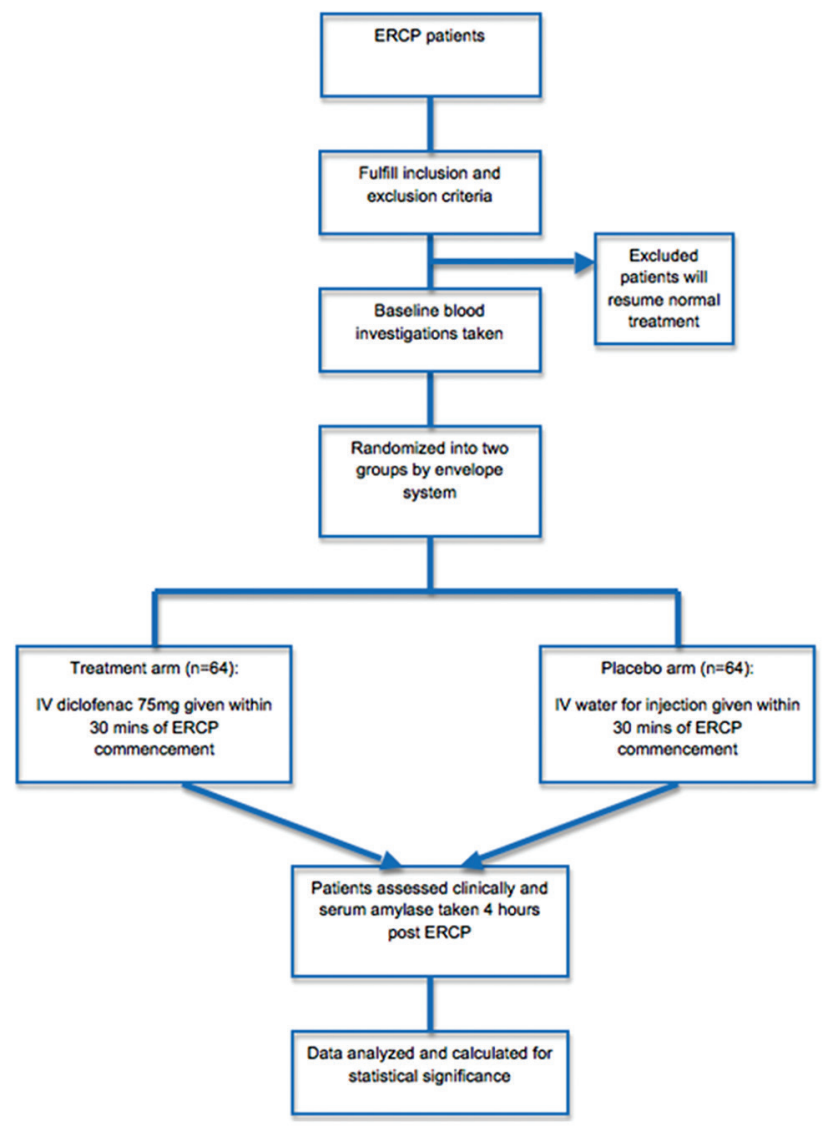

Fig. 1: Flowchart for methodology for residual stones with stent removal (28 or 23\%), patients who were reassessed and reinserted with a new stent (15 or $12.3 \%$ ), for cholangitis ( 9 or $7.4 \%$ ), for assessment and insertion of stent (7 or $5.7 \%$ ), and for patients who underwent pancreatic duct stenting ( 3 or $2.5 \%$ ) (Table 1 ).

\section{Post-ERCP results}

Patients given diclofenac sodium within 30 minutes of procedure have less incidence of PEP post-ERCP, with $3(5.1 \%)$ in the treatment arm in comparison to $8(12.7 \%)$ in the placebo arm. Although there is a $7.6 \%$ difference, it is not statistically significant. It is noted, however, an increase in hyperamylesemia in the treatment arm, (9 patients or $15.3 \%$ ) in comparison to the placebo arm (6 patients or 9.5\%). This difference was also not statistically significant. There was no significant difference in epigastric pain between the treatment and placebo arm, with most of the patients, not having any epigastric pain after the ERCP procedure. One patient had developed allergic reaction to diclofenac sodium but was amenable to treatment (Tables 2 and 3 ).

Table 1: Distribution for treatment and placebo group

\begin{tabular}{|c|c|c|c|}
\hline \multirow[t]{2}{*}{ Patient characteristics } & \multicolumn{2}{|c|}{$\begin{array}{l}\text { Diclofenac } \\
\text { sodium (Voltaren) }\end{array}$} & \multirow[t]{2}{*}{ p value } \\
\hline & Yes n (\%) & No n (\%) & \\
\hline \multicolumn{4}{|l|}{ Race } \\
\hline Malay & $36(61)$ & $33(52.4)$ & 0.324 \\
\hline Chinese & 17 (28.8) & $27(42.9)$ & \\
\hline Indian & $3(5.1)$ & $2(3.2)$ & \\
\hline Others & $3(5.1)$ & $1(1.6)$ & \\
\hline \multicolumn{4}{|l|}{ Age } \\
\hline $18-30$ & $4(6.8)$ & $4(6.3 \%)$ & 0.304 \\
\hline $31-40$ & 11 18.6) & $11(17.5)$ & \\
\hline $41-50$ & 7 (11.9) & $7(11.1)$ & \\
\hline $51-60$ & $13(22)$ & $10(15.9)$ & \\
\hline $61-70$ & $18(30.5)$ & $14(22.2)$ & \\
\hline $71-80$ & $6(10.2)$ & $17(27)$ & \\
\hline Mean age (SD) & $52.86(15.4)$ & $55.70(16.76)$ & \\
\hline \multicolumn{4}{|l|}{ Gender } \\
\hline Male & $26(44.1)$ & $35(57.4)$ & 0.205 \\
\hline Female & $33(55.9)$ & $28(44.4)$ & \\
\hline \multicolumn{4}{|l|}{ Comorbid } \\
\hline Yes & $26(44.1)$ & $32(50.8)$ & 0.457 \\
\hline No & $33(55.9)$ & $31(49.2)$ & \\
\hline \multicolumn{4}{|l|}{ Reason for ERCP } \\
\hline Cholangitis & $3(5.1)$ & $6(9.5)$ & 0.873 \\
\hline Obstructive jaundice & $28(47.5)$ & $32(50.8)$ & \\
\hline $\begin{array}{l}\text { Assessment/insertion } \\
\text { of stent }\end{array}$ & $4(6.8)$ & $3(4.8)$ & \\
\hline $\begin{array}{l}\text { Reassessment/removal } \\
\text { of stent }\end{array}$ & $15(25.4)$ & $13(20.6)$ & \\
\hline $\begin{array}{l}\text { Reassessment/change } \\
\text { of stent }\end{array}$ & 7 (11.9) & 8 (12.7) & \\
\hline Pancreatic duct stenting & $2(3.4)$ & $1(1.6)$ & \\
\hline
\end{tabular}

Table 2: Post-ERCP pancreatitis rates in treatment and placebo group

\begin{tabular}{|c|c|c|c|c|}
\hline \multirow[t]{2}{*}{ Medication } & \multicolumn{2}{|c|}{ Pancreatitis } & \multirow[t]{2}{*}{ Total } & \multirow[t]{2}{*}{ p value } \\
\hline & Yes & No & & \\
\hline \multicolumn{5}{|l|}{ Voltaren } \\
\hline Yes & & & & 0.142 \\
\hline Count & 3 & 56 & 59 & \\
\hline \% within Voltaren & $5.1 \%$ & $94.9 \%$ & $100.0 \%$ & \\
\hline \multicolumn{5}{|l|}{ No } \\
\hline Count & 8 & 55 & 63 & \\
\hline \% within Voltaren & $12.7 \%$ & $87.3 \%$ & $100.0 \%$ & \\
\hline
\end{tabular}




\section{DISCUSSION}

ERCP is one of few common causes of acute PEP. ERCP may also cause hyperamylasemia and, hence, must be differentiated from acute PEP by fulfilling 2 out of 3 of the following criteria [11]:

1. Abdominal pain, which is usually acute in onset, and mainly in the epigastric region that mostly radiates to the back

2. Serum lipase/amylase activity that is 3 times the upper limit of normal

3. Characteristics of PEP, which is seen on imaging (either abdominal ultrasonography, computed tomography, or magnetic resonance imaging)

The pathophysiology of PEP post-ERCP is thought to be due to hydrostatic injury or from direct manipulation of the pancreatic duct [12]. Injury to the papilla or ampulla, either mechanical (from repeated manipulation or instrumentation of pancreatic duct) [13] or thermal (during electrocautery) [14] can cause pancreatic secretions to be impaired. During diagnostic ERCP or sphincter of Oddi manometry, over-injection of the pancreatic duct may lead to hydrostatic injury [15] - another important cause of pancreatic post-ERCP.

Factors that increase the risk of post-ERCP PEP can be divided into three factors: Operator-related, patient-related, or procedure-related factors [16-18] (Table 4).

Patients are placed into the high-risk category when the following occur during ERCP:

1. Suspected sphincter of Oddi dysfunction

2. Difficult cannulation

3. Previous post-ERCP PEP

In previous studies, suppository Voltaren was shown to have a role in reducing the incidence of post-ERCP PEP, although mostly not statistically significant. In two meta-analysis, overall benefit is seen in

Table 3: Post-ERCP hyperamylasemia rates in treatment and placebo group

\begin{tabular}{lllll}
\hline Medication & \multicolumn{2}{c}{ Hyperamylasemia } & \multirow{2}{*}{ Total } & p value \\
\cline { 2 - 3 } & Yes & No & & \\
\hline $\begin{array}{lllll}\text { Voltaren } \\
\quad \text { Yes }\end{array}$ & & & & 0.142 \\
$\quad$ Count & 9 & 50 & 59 & \\
$\quad$ \% within Voltaren & $15.3 \%$ & $84.7 \%$ & $100.0 \%$ & \\
$\quad$ No & & & & \\
$\quad$ Count & 6 & 57 & 63 & \\
$\quad \%$ within Voltaren & $9.5 \%$ & $90.5 \%$ & $100.0 \%$ & \\
\hline
\end{tabular}

ERCP: Endoscopic retrograde cholangiopancreatography

Table 4: Risk factors for post-ERCP

\begin{tabular}{|c|c|c|}
\hline Operator-related & Patient-related & Procedure-related \\
\hline $\begin{array}{l}\text { Inadequate training } \\
\text { Lack of experience }\end{array}$ & $\begin{array}{l}\text { Younger age } \\
\text { Female sex } \\
\text { Normal serum } \\
\text { bilirubin } \\
\text { Recurrent } \\
\text { pancreatitis } \\
\text { Prior } \\
\text { ERCP-induced } \\
\text { pancreatitis } \\
\text { Sphincter of Oddi } \\
\text { dysfunction }\end{array}$ & $\begin{array}{l}\text { Difficult cannulation } \\
\text { Pancreatic duct } \\
\text { injection } \\
\text { Sphincter of Oddi } \\
\text { manometry } \\
\text { Precut } \\
\text { sphincterotomy } \\
\text { Pancreatic } \\
\text { sphincterotomy } \\
\text { Minor papilla } \\
\text { sphincterotomy } \\
\text { Biliary balloon } \\
\text { sphincteroplasty } \\
\text { Ampullectomy }\end{array}$ \\
\hline
\end{tabular}

ERCP: Endoscopic retrograde cholangiopancreatography its forest plot, favoring rectal NSAIDs in the reduction of PEP $[8,9,19,20]$. In previous studies, NSAIDs were given through a different route or patients were given a different form of IV NSAID. Up to the conception and design of this study, there were no studies that involved the usage of IV diclofenac sodium.

There was an improvement in the incidence of PEP with IV diclofenac. Numbers may not have been significant due to overall number of patients recruited into the study, and an overall low rate of PEP in this center. Previously, our center's rate of PEP was $15 \%$ in 2012 , showing an improvement most likely due to physician improvement in performing procedure and increased experience in handling ERCP. PEP in the placebo group was only $12.7 \%$. Although pancreatitis rates are acceptable up to $10 \%$, most reported studies have a PEP rate up to $26 \%$ [21], and in this study, rectal diclofenac was shown to be beneficial.

Another limitation of this study is patients who are at high risk for PEP was not screened initially and noted during collection of data. In previous studies [22], factors that increased risk for PEP were studied, and hence, a more in-depth look at the usage of diclofenac can be looked at in decreasing PEP incidence. A further study can be conducted to correlate the efficacy of IV diclofenac in patients who are high risk of PEP. There was no incidence of severe PEP in both arms; hence, no conclusion can be made regarding reducing the severity of PEP in this study.

IV diclofenac has not been used before this, as its efficacy is uncertain due to rapid decrease in bioavailability after administration. Willis et al. [23] had shown the two concentrations of IV diclofenac $50 \mathrm{mg}$ versus oral diclofenac $50 \mathrm{mg}$ in bloodstream after administration in human candidates (Figs. 2-4). In another study by Morimoto et al. [24], it can be seen that plasma concentration levels are higher and stay longer in the blood after suppository diclofenac sodium. Even though plasma levels decline quickly after administration, it may not be a clear indicator of its efficacy. For example, the oral diclofenac produces a quick drop after the $3^{\text {rd }} \mathrm{h}$ but has continuous analgesic effect even after its plasma levels are on the decline. Hence, its full efficacy is unable to be quantified. For this reason, IV diclofenac sodium was served within 30 min of ERCP, but perhaps more specifically; it should be administered around the time of cannulation of the bile ducts and cholangiography. The effects of diclofenac would be most important during this period to prevent PEP as sequelae of ERCP. To further clarify this issue, a direct comparison study between IV versus rectal diclofenac sodium should be performed.

Theoretically, reduction in the incidence of PEP should occur as NSAIDs are thought to reduce inflammation. If bioavailability was to be considered as a factor, previous study using oral diclofenac

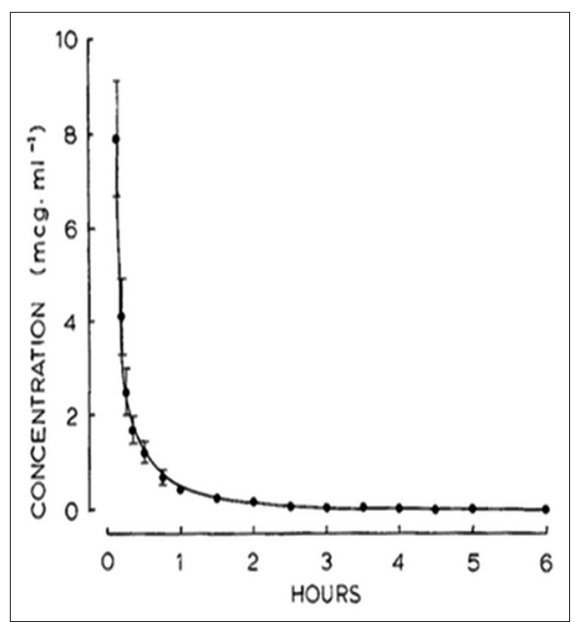

Fig. 2: Mean plasma concentration of diclofenac in seven healthy female volunteers following an intravenous injection of $50 \mathrm{mg}$ diclofenac sodium [23] 


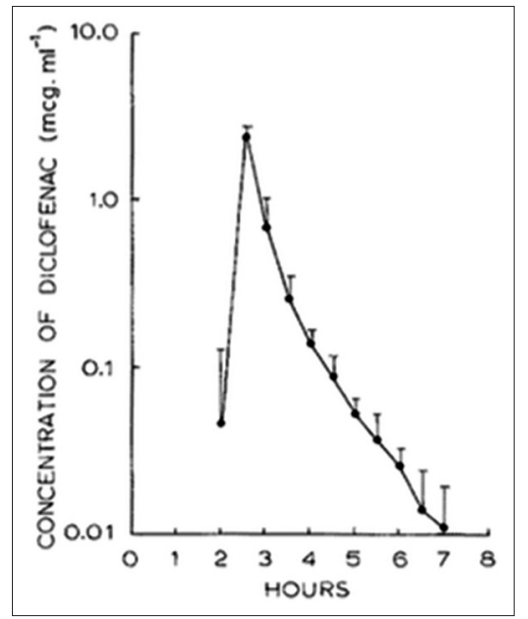

Fig. 3: Mean plasma levels of diclofenac following single oral $50 \mathrm{mg}$ doses. Drug level curves are normalized around time of peak drug levels [23]

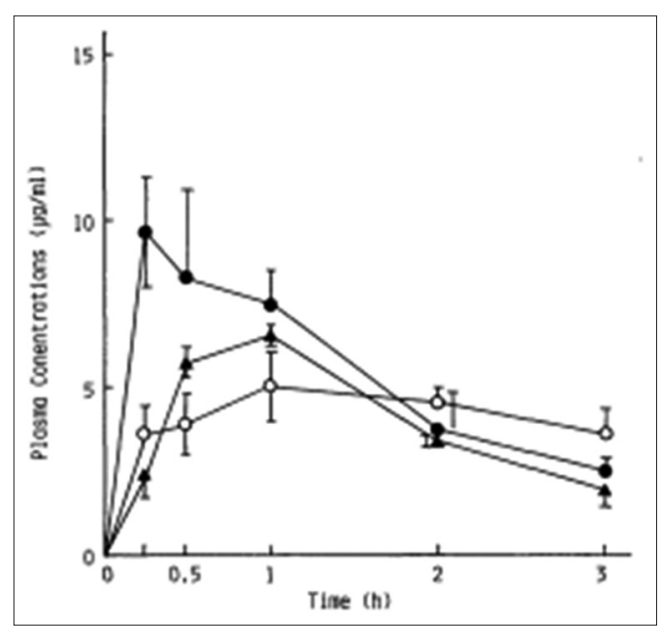

Fig. 4: Plasma concentration of diclofenac following rectal administrations of diclofenac sodium gel preparation and a commercial suppository in a man [24]

sodium [25] showed that there was improvement, but no difference statistically. Studying mean plasma levels of oral diclofenac sodium, one may postulate that timing of administration may change outcome for patients. It is clear that among the three options of administration that rectal form gives a more steady state and likely the reason of better prevention. It is important to produce a steady state of plasma levels, especially when cannulation of the bile duct may be difficult and may take longer than anticipated. This, in turn, reduces its bioavailability if timing of cannulation and injection of contrast is prolonged. As mentioned previously, plasma mean levels may be low in the blood, but its effects whether due to direct effect or from its metabolites are not well known.

As PEP is defined by fulfillment of 2 out of 3 criteria [11], additional imaging should be done to confirm the presence of PEP. Diclofenac sodium being also an analgesic could blunt the perception of pain in the patient and hence under-reported as PEP, but instead labeled has hyperamylasemia. The cause of increased amylase can actually be further tested by simple agarose gel electrophoresis [26] to differentiate possible causes and further pinpoint as due to PEP.

Diclofenac sodium is a relatively safe and cheap drug to be used, in most cases for its analgesic purposes, but will need further studies to determine if IV diclofenac sodium is beneficial in improving the rates of
PEP. It should, however, be used with caution as it may develop allergic reactions; skin rashes, angioedema, pneumonitis, and also anaphylactic reaction, leading to death [27].

\section{CONCLUSION}

In this study, IV diclofenac sodium decreases the rate of post-ERCP PEP. However, it is not statistically significant and further study with a larger sample size can be performed to check if IV diclofenac is beneficial.

\section{AUTHOR'S CONTRIBUTIONS}

Chik Ian - data collection and processing and writing of manuscript. Razman Jarmin - conception of idea and contribution to discussion of manuscript. Affirul Ariffin - conception of idea and contribution to discussion of manuscript. Hairol Othman - performed ERCP for the collection of data and data processing. Zamri Zuhdi - performed ERCP for the collection of data and data processing. Azlanudin Azman - performed ERCP for the collection of data and contribution to discussion of manuscript. Nik Ritza Kosai Nik Mahmood - proof reading of manuscript.

\section{CONFLICTS OF INTEREST}

The authors declare that they have no conflicts of interest.

\section{REFERENCES}

1. Rabenstein T, Schneider HT, Bulling D, Nicklas M, Katalinic A, Hahn EG, et al. Analysis of the risk factors associated with endoscopic sphincterotomy techniques: Preliminary results of a prospective study, with emphasis on the reduced risk of acute pancreatitis with low-dose anticoagulation treatment. Endoscopy 2000;32:10-9.

2. Vandervoort J, Soetikno RM, Tham TC, Wong RC, Ferrari AP Jr. Montes $\mathrm{H}$, et al. Risk factors for complications after performance of ERCP. Gastrointest Endosc 2002;56:652-6.

3. Wang P, Li ZS, Liu F, Ren X, Lu NH, Fan ZN, et al. Risk factors for ERCP-related complications: A prospective multicenter study. Am J Gastroenterol 2009:104:31-40.

4. Cotton PB, Garrow DA, Gallagher J, Romagnuolo J. Risk factors for complications after ERCP: A multivariate analysis of 11,497 procedures over 12 years. Gastrointest Endosc 2009;70:80-8.

5. Andriulli A, Loperfido S, Napolitano G, Niro G, Valvano MR, Spirito F, et al. Incidence rates of post-ERCP complications: A systematic survey of prospective studies. Am J Gastroenterol 2007;102:1781-8.

6. Enochsson L, Swahn F, Arnelo U, Nilsson M, Löhr M, Persson G, et al. Nationwide, population-based data from 11,074 ERCP procedures from the Swedish registry for gallstone surgery and ERCP. Gastrointest Endosc 2010;72:1175-84, 1184.e1-3.

7. Fogel EL, Eversman D, Jamidar P, Sherman S, Lehman GA. Sphincter of oddi dysfunction: Pancreat obiliary sphincterotomy with pancreatic stent placement has a lower rate of pancreatitis than biliary sphincterotomy alone. Endoscopy 2002;34:280-5.

8. Ding X, Chen M, Huang S, Zhang S, Zou X. Nonsteroidal antiinflammatory drugs for prevention of post-ERCP pancreatitis: A metaanalysis. Gastrointest Endosc 2012;76:1152-9.

9. Yaghoobi M, Rolland S, Waschke KA, McNabb-Baltar J, Martel M, Bijarchi R, et al. Meta-analysis: Rectal indomethacin for the prevention of post-ERCP pancreatitis. Aliment Pharmacol Ther 2013;38:995-1001.

10. Senol A, Saritas U, Demirkan H. Efficacy of intramuscular diclofenac and fluid replacement in prevention of post-ERCP pancreatitis. World J Gastroenterol 2009:15:3999-4004

11. Banks PA, Bollen TL, Dervenis C, Gooszen HG, Johnson CD, Sarr MG, et al. Classification of acute pancreatitis--2012: Revision of the Atlanta classification and definitions by international consensus. Gut 2013;62:102-11

12. Sherman S, Lehman GA. ERCP- and endoscopic sphincterotomyinduced pancreatitis. Pancreas 1991;6:350-67.

13. Johnson GK, Geenen JE, Johanson JF, Sherman S, Hogan WJ, Cass $\mathrm{O}$, et al. Evaluation of post-ERCP pancreatitis: Potential causes noted during controlled study of differing contrast media. Midwest pancreaticobiliary study group. Gastrointest Endosc 1997;46:217-22.

14. Ratani RS, Mills TN, Ainley CC, Swain CP. Electrophysical factors influencing endoscopic sphincterotomy. Gastrointest Endosc 1999;49:43-52. 
15. Sherman S, Hawes RH, Troiano FP, Lehman GA. Pancreatitis following bile duct sphincter of oddimanometry: Utility of the aspirating catheter. Gastrointest Endosc 1992;38:347-50.

16. Badalov N, Tenner S, Baillie J. The Prevention, recognition and treatment of post-ERCP pancreatitis. JOP 2009;10:88-97

17. Testoni PA, Mariani A, Giussani A, Vailati C, Masci E, Macarri G, et al. Risk factors for post-ERCP pancreatitis in high- and low-volume centers and among expert and non-expert operators: A prospective multicenter study. Am J Gastroenterol 2010;105:1753-61.

18. Mariani A, Giussani A, Di Leo M, Testoni S, Testoni PA. Guidewire biliary cannulation does not reduce post-ERCP pancreatitis compared with the contrast injection technique in low-risk and high-risk patients. Gastrointest Endosc 2012; 75:339-46.

19. Yu LM, Zhao KJ, Lu B. A use of NSAIDs via the rectal route for the prevention of pancreatitis after ERCP in all-risk patients: An updated meta-analysis. Gastroenterol Res Pract 2018;2018:1027530.

20. Yang C, Zhao Y, Li W, Zhu S, Yang H, Zhang Y, et al. Rectal nonsteroidal anti-inflammatory drugs administration is effective for the prevention of post-ERCP pancreatitis: An updated meta-analysis of randomized controlled trials. Pancreatology 2017;17:681-8.

21. Khoshbaten M, Khorram H, Madad L, Ehsani Ardakani MJ, Farzin H, Zali MR, et al. Role of diclofenac in reducing post-endoscopic retrograde cholangiopancreatography pancreatitis. J Gastroenterol
Hepatol 2008;23:e11-6.

22. Otsuka T, Kawazoe S, Nakashita S, Kamachi S, Oeda S, Sumida C, et al. Low-dose rectal diclofenac for prevention of post-endoscopic retrograde cholangiopancreatography pancreatitis: A randomized controlled trial. J Gastroenterol 2012;47:912-7.

23. Willis JV, Kendall MJ, Flinn RM, Thornhill DP, Welling PG. The pharmacokinetics of diclofenac sodium following intravenous and oral administration. Eur J Clin Pharmacol 1979;16:405-10.

24. Morimoto K, Iwamoto Y, Katashima T, Takeeda T, Nakamoto Y, Morisaka $\mathrm{K}$, et al. Absorption and bioavailability of diclofenac after rectal administration of diclofenac-na gel preparation in rat and man. Pharm Res 1985;2:166-70.

25. Cheon YK, Cho KB, Watkins JL, McHenry L, Fogel EL, Sherman S, et al. Efficacy of diclofenac in the prevention of post-ERCP pancreatitis in predominantly high-risk patients: A randomized double-blind prospective trial. Gastrointest Endosc 2007;66:1126-32.

26. Ka AS, Sapkota S, William E. Iso-amylase electrophoretic patterns in hyperamylasemia conditions-a leading footprint. Asian J Pharm Clin Res 2015;8:83-5.

27. Deepalatha C, Prasa RV, Chandra S, Mohan PM, Lakshmi V. Diclofenac-induced urticaria in paediatric patient. Asian J PharmClin Res 2013;6:1-2. 